\title{
SURGICAL APPROACHES TO TUMORS AND EPILEPTOGENIC ZONES CLOSE TO WERNICKE'S AREA
}

\author{
ARTHUR CUKIERT, GARY GRONICH, RAUL MARINO JR
}

\begin{abstract}
SUMMARY - Surgical procedures near to language related brain regions may cause severe morbidity in relation to speech. Operations performed under local anesthesia and intraoperative cortical mapping may minimize these risks. Six patients with tumors near the Wernicke's area were treated ( 2 low-grade astrocytomas, 1 ganglioglioma, 1 xanthoastrocytoma, 1 metastasis, 1 glioblastoma). Their clinical presentation consisted of epilepsy $(n=4)$ and dysphasia $(n=2)$. The skin and periosteum were infiltrated with local anesthetic and an ample craniotomy was performed. Cortical stimulation with an unipolar electrode was then carried out with concomitant speech testing (mainly comprehension and sequential speech). After mapping, the best surgical approach aiming to avoid the mapped area was elected. In 5 cases the resection was total and in 1, partial (glioblastoma). There was a transitory ( 10 days) worsening of the pre-operative deficit in 1 case (glioblastoma). In 3 patients, the speech areas were displaced: posteriorly $(n=2)$ or anteriorly $(n=1)$. Surgical procedures under local anesthesia are safe and may avoid post-operative language disturbances in patients with tumors near to Wernicke's area.
\end{abstract}

KEY WORDS: brain tumors, epilepsy, Wernicke's area, cortical mapping.

\section{Abordagens cirúrgicas a tumores e zonas epileptógenas junto à área de Wernicke}

RESUMO - A ressecção de processos expansivos em áreas relacionadas à fala pode causar morbidade severa de linguagem. A realização de procedimentos cirúrgicos sob anestesia local e mapeamento intra-operatório das áreas relacionadas à linguagem pode ser empregada para minimizar estes déficits. Seis pacientes com tumores da área de Wernicke foram mapeados (2 astrocitomas de baixo grau, 1 ganglioglioma, 1 xantoastrocitoma, 1 metástase, 1 glioblastoma). Sua apresentação clínica incluía epilepsia $(n=4)$ e disfasia de compreensão $(n=2)$. Após infiltração dos planos superficiais com anestésico local e craniotomia, procedia-se à estimulação com eletrodo unipolar do córtex temporal amplamente exposto, com testagem simultânea de linguagem, principalmente compreensão e fala sequencial. Após o mapeamento, elegia-se a melhor via de acesso de modo a evitar a área mapeada. Em 5 casos a resseç̧ão foi completa e em 1 parcial (glioblastoma). Em 1 caso houve piora transitória (10 dias) de déficit pré-existente de compreensão e expressão (glioblastoma). Em 3 casos as áreas da fala haviam sido deslocadas: posteriormente $(n=2)$ ou em direçāo suprasilviana $(n=1)$. Procedimentos cirúrgicos com anestesia local são seguros e podem evitar distúrbios pós-operatónios de linguagem em pacientes com tumores próximos à área de Wernicke.

PALAVRAS-CHAVE: tumores cerebrais, epilepsia, área de Wernicke, mapeamento cortical.

The resection of lesions or cortex adjacent to speech related areas can cause language disturbances. At the early period of epilepsy surgery the majority of the procedures were performed under local anesthesia and included extensive intraoperative cortical mapping ${ }^{\not}$. The motor and sensitive homunculi and the main speech-related and modality-specific areas were determined by these studies

Division of Neurosurgery, Department of Neurology, Faculty of Medicine, University of São Paulo. Aceite: 10-abril-1995. 
pioneered by the Penfield's group. More recently, the number of temporal lobe resections carried out under general anesthesia is rapidly increasings. Procedures under local anesthesia are now used mainly in the treatment of lesions or epilepsies in the Wernicke's or Broca's areas ${ }^{2}$. Only $6 \%$ of the patients are now operated under local anesthesia in our Center. General anesthesia provides more comfort for the patient and the surgeon. On the other hand, it is impossible to monitor speech while using general anesthesia.

This paper discusses the usefulness of intraoperative cortical mapping under local anesthesia in patients with lesions in speech-related areas.

\section{METHODS}

Six patients with tumors of the Wernicke's area were operated and mapped under local anesthesia ( 2 low-grade astrocytomas, 1 ganglioglioma, 1 xanthoastrocytoma, 1 metastasis, 1 glioblastoma) (Table 1). Their clinical presentation included epilepsy $(n=4)$ and receptive dysphasia $(n=2)$.

After infiltration of the skin and periosteum with local anesthetic, an ample craniotomy was performed and the cortex widely exposed. The motor and language-related areas were then mapped by means of stimulation using a unipolar carbon ball-electrode. Stimulus frequency ranged from 1 to $60 \mathrm{~Hz}$ and intensity from 3 to 12 $\mathrm{mA}$. Positive motor responses included muscle twitches in the correspondent topography of the homunculus. Speech-related areas were determined as those where an aphasic block could be obtained after brief stimuli. After mapping, the best surgical approach was elected as to avoid speech areas.

Table 1. Clinical summary of the reported patients.

\begin{tabular}{ccccc}
\hline Patient & Topography & Pathology & Surgery & Results \\
\hline I & T2/T3 Post. & Astrocytoma & Lesionectomy & Seizure free \\
II & T1/T2 Post. & Ganglioglioma & Lesion + Margin & Seizure free \\
III & Fusif/Parahip & Xanthoastrocytoma & Lesion + Margin & Seizure free \\
IV & Fusif/Parahip & Ganglioglioma & Lesion + Margin & Seizure free \\
V & T1/T2 Post. & Metastasis & Lesionectomy & Seizure free \\
VI & Parietal & Glioblastoma & Partial resec. & Rare seizures \\
\hline
\end{tabular}

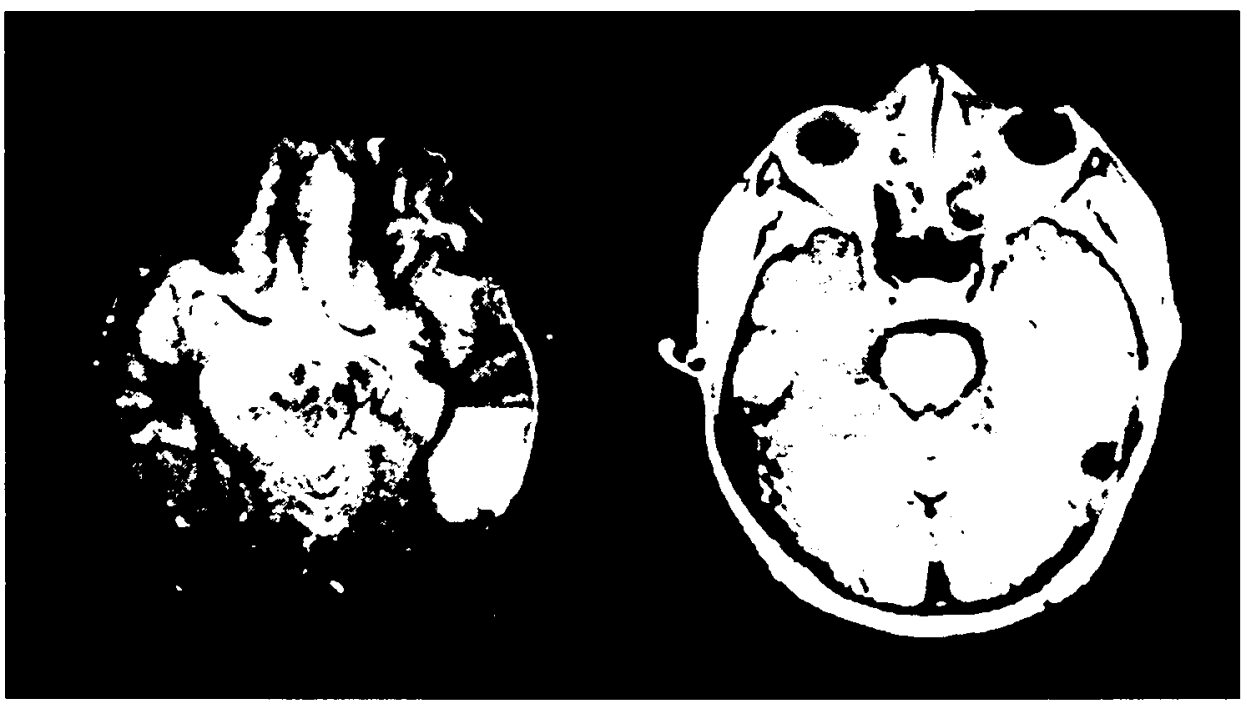

Fig 1.Pre-(lefi) and late ( 3 years) post-operative (right) MRI of a patient with a tumor near Wernicke's area. 


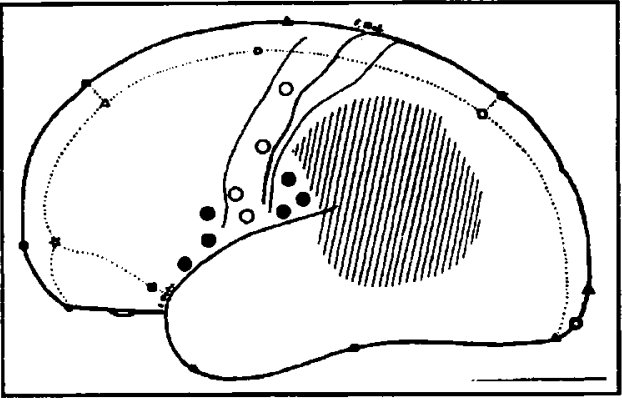

Fig 2. Diagram showing the intraoperative cortical mapping under local anesthesia in a patient with glioblastoma. Resection was partial (>90\%) since part of the tumor encroached Wernicke's area. Wernicke's was displaced anteriorly towards the central sulcus. Hatched area $=$ tumor $;$ open circles $=$ motor strip; black circles $=$ speech areas.
Electrocorticography was also used to map the epileptogenic area in those patients presenting with epilepsy.

\section{RESULTS}

In five patients a total removal of the lesion and epileptogenic cortex was performed and in 1 (glioblastoma) the resection was partial (Fig 1). There was a transient increase (10 days) in the already present pre-operative dysphasia in 1 patient (glioblastoma) (Fig 2); in the others, there was no additional speech deficit. In 3 patients, Wernicke's area was displaced: posteriorly $(n=2)$ (Fig 3) or in the suprasylvian direction $(n=1)$ (Fig 4).
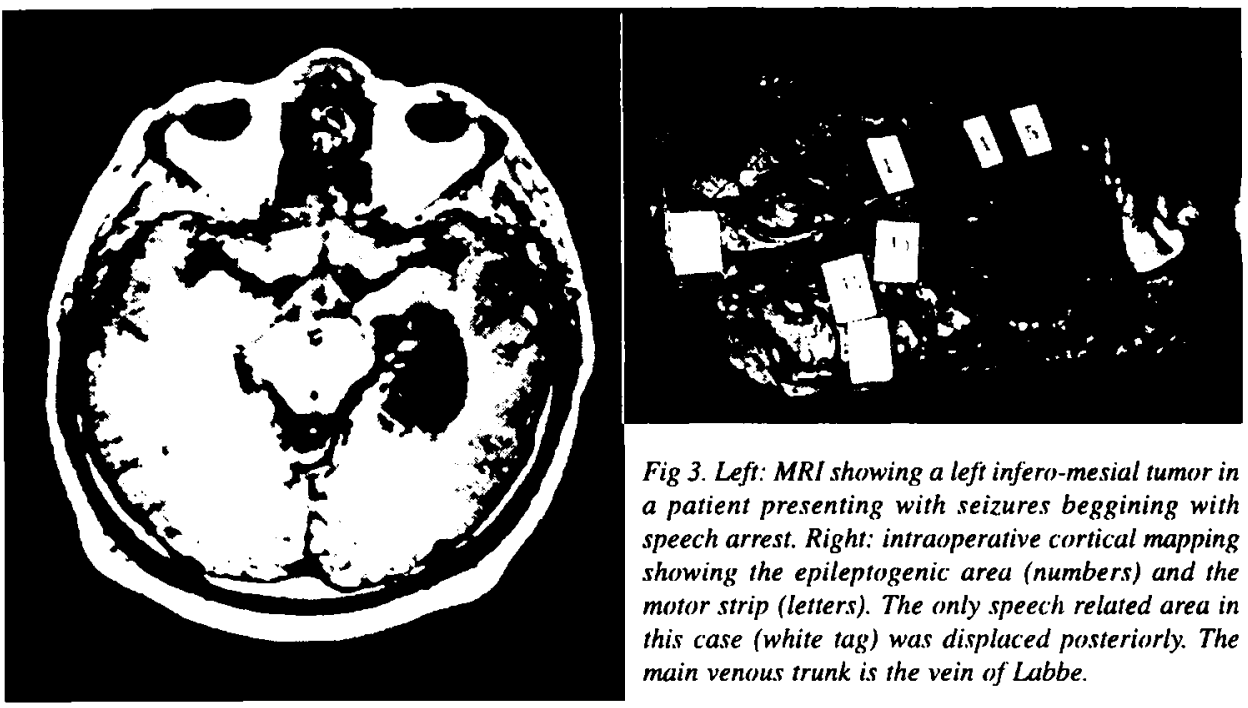

Fig 3. Left: MRI showing a left infero-mesial tumor in a patient presenting with seizures beggining with speech arrest. Right: intraoperative cortical mapping showing the epileptogenic area (numbers) and the motor strip (letters). The only speech related area in this case (white tag) was displaced posteriorly. The main venous trunk is the vein of Labbe.
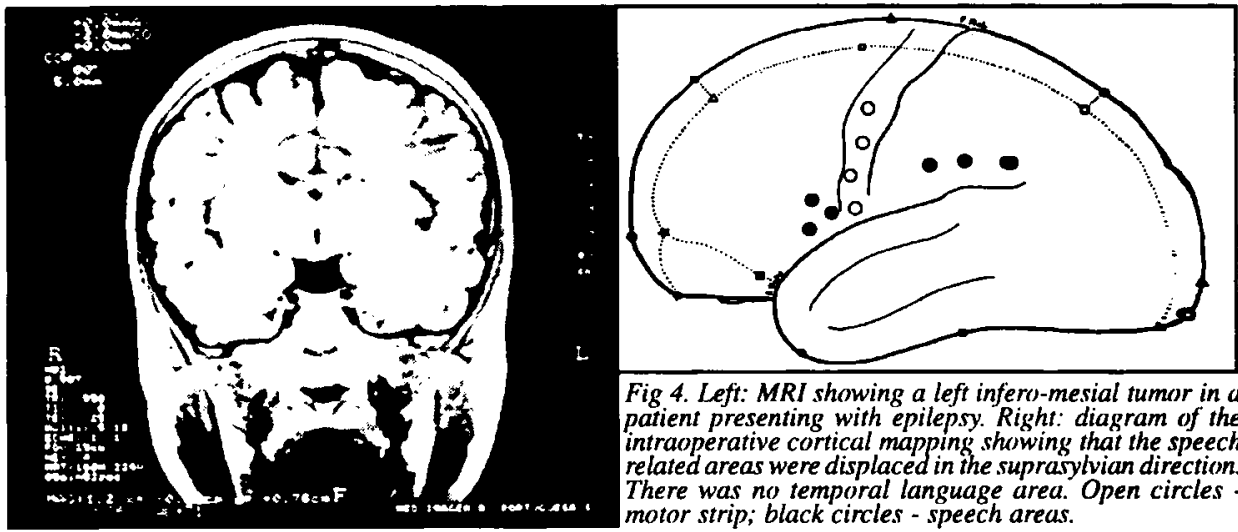

Fig 4. Left: MRI showing a left infero-mesial tumor in a patient presenting with epilepsy. Right: diagram of the intraoperative cortical mapping showing that the speech related areas were displaced in the suprasylvian direction. There was no temporal language area. Open circles. motor strip; black circles - speech areas. 


\section{COMMENTS}

Surgery under local anesthesia and cortical mapping can be safely performed and may avoid language-related morbidity in patients with tumors or epilepsies in Wernicke's or Broca's areas'.

Speech deficits can occur after surgery in these eloquent areas ${ }^{10}$. Aphasia may be the result of the direct destruction of the language-related cortex (which is minimized by cortical mapping)', inappropriate vascular occlusion (specially main veins) or after distortion of the brain parenchyma after extensive tumor debulking. The deficit is usually transitory after parenchymal distortion. This happened in the patient with glioblastoma, where an extensive debulking of a huge tumor occupying the entire left parietal lobe was performed. On the other hand, this is often not the case when the eloquent cortex itself was resected or had major ischemia.

Dichotic listening ${ }^{3}$ and intracarotid sodium amytal ${ }^{15}$ tests are able to determine the speech hemispheric lateralization, but can not determine the exact topography of these regions. Functional magnetic resonance imaging and positron emission tomography are able to further localize them but an exact correlation of these imaging techniques to the exposed cortex is not yet possible ${ }^{6}$. Anatomic asymmetries ${ }^{13}$, now perfectly shown with current imaging techniques (specially MRI) may add to the our hemispheric lateralization capability.

Luders et $\mathrm{al}^{7}$ have recognized a temporo-basal specch area after chronic stimulation with subdural electrodes in addition to the classic Broca's and Wernicke's areas. On the other hand, removal of this recently recognized temporo-basal speech area has not been associated to any detectable language disturbance as is often seen after injury to Broca's or Wernicke's areas or its connections ${ }^{11,14}$.

In patients bearing intracranial tumors at or near to speech areas ${ }^{4}$ cortical mapping seems to be even more relevant since these regions could be displaced by the lesion from their original position. Exclusively suprasylvian speech areas are uncommon in patients without tumors (even in epileptics) but can be seen in patients with tumors.

Speech deficits are not necessarily related to verbal memory disturbances. The latter can occur after resections restricted to the amygdalo-hippocampal region or to cortical regions not related to speech. Cortical resections kept at least $1 \mathrm{~cm}$ away from the intraoperatively mapped speech areas are safe ${ }^{12}$.

In patients with lesions of the Wernicke's area presenting with epilepsy, intraoperative electrocorticography and cortical mapping of motor and speech areas under local anesthesia may maximize the resection and offer excellent results in relation to the epilepsy and the tumor.

\section{REFERENCES}

1. Adams CBT. The surgery for epilepsy with speech arrest. Acta Neurochirur 1993, 56(Suppl):72-82.

2. Burchiel KJ, Clark H, Ojemann GA. Use of stimulation mapping and corticography in the excision of arteriovenous malformation in sensorimotor and language related neocortex. Neurosurgery 1989, 24:323-327.

3. Caner-Cukiert AR, Cukiert A. Dichotic words listening test. technical aspects and results in normal right handed individuals. Arq Neuropsiquiatr 1994, 52:204-209.

4. Haglund MM, Berger MS, Shamseldin M, Lettich E, Ojemann GA. Cortical localization of temporal lobe language sites in patients with glioma. Neurosurgery 1994, 34:567-576.

5. Heilman KM, Wilder BJ, Malzone WF. Anomic aphasia following anterior temporal lobectomy. Trans Am Neurol Assoc 1972, 97:291-293.

6. Lesser H, Lueders H, Dinner DS. The location of speech and writing functions in the frontal language area: results of extraoperative cortical stimulation. Brain 1984, 107:275-291.

7. Lueders H, Lesser RP, Hahn J. Basal temporal language area demonstrated by electrical stimulation. Neurology 1986, 36:505-510.

8. Ojemann GA. Brain organization for language from the perspective of electrical stimulation mapping. Behav Brain Sci 1983, 6:189-206. 
9. Ojemann GA, Dodrill CB. Intraoperative techniques for reducing language and memory deficits with left temporal lobectomy. Adv Epileptol 1987, 16:327-330.

10. Ojemann GA, Creutzfeld $O$, Lettich E. Neuronal activity in human lateral temporal cortex related to short term verbal memory, naming and reading. Brain 1988, 111:1383-1403.

11. Ojemann GA, Ojemann JG, Lettich E, Berger MS. Cortical language localization in the left, dominant hemisphere. J Neurosurg 1989, 71:316-326.

12. Ojemann GA. Cortical organization of language. J Neurosei 1991, 11:281-287.

13. Rubens AB, Mahowald MW, Hutton JT. Asymmetry of the lateral (sylvian) fissures in man. Neurology 1976, 26:620-624.

14. Van Buren JM, Fedio P, Frederick GC. Mechanism and localization of speech in the parietotemporal cortex. Neurosurgery 1978, 2:233-239.

15. Wada J, Rasmussen T. Intracarotid injections of sodium amytal for the lateralization of cerebral speech dominance. J Neurosurg 1960, 17:266-282. 